\title{
Variables Impacting Lymph Node Recovery in Colectomy Resection Specimens Removed for Colorectal Adenocarcinoma
}

\author{
Grant Schafer ${ }^{1}$, Bruce F Kimler ${ }^{2}$, Douglas H McGregor ${ }^{3}$, Fang Fan ${ }^{1}$ and Ossama Tawfik ${ }^{*}, 1$
}

Departments of ${ }^{1}$ Pathology and Laboratory Medicine, ${ }^{2}$ Radiation Oncology, The University of Kansas Medical Center, Kansas City, Kansas, USA, and Department of ${ }^{3}$ Pathology, The Kansas City Veterans Affairs Medical Center, Kansas City, Missouri, USA

\begin{abstract}
Background: Recent data suggest that a higher number of nodes evaluated in colectomy specimens for colorectal adenocarcinoma is associated with increased survival. Recommendations mandate the harvesting of at least 12 nodes in colectomy specimens for adequate assessment. Recent studies argue that the above association is complex and is uncontrolled for a variety of variables.

Objective: The study's objective is to evaluate several factors that impact the harvesting of lymph nodes in colectomy specimen.

Patients: We reviewed 306 colectomy specimens from 2 academic medical centers, 177 from Kansas University Medical Center (KUMC) and 129 from the Kansas City Veterans Affairs Medical Center (VAMC) from 2000 to 2007.

Design: Factors evaluated included tumor size, grade, stage, site, number of positive nodes and length of colectomy segment removed. We compared the number of nodes removed at the 2 institutions and whether individual surgeons had an impact on the number of harvested nodes.

Results: Harvesting at least 12 nodes is correlated with larger tumor size, higher grade and stage and specimens longer than $21 \mathrm{~cm}$. More nodes were harvested from the right colon (mean=13 nodes), followed by descending (12 nodes), transverse and rectosigmoid (10 nodes each). Number of positive nodes correlated with tumor grade, but not with tumor site, size, linear length of specimen or whether 12 nodes were harvested.

Cases from the VAMC were more likely to harvest 12 nodes compared to KUMC. It was noted that 2 of 10 surgeons at the VAMC performed $76 \%$ of all surgeries. There were 21 surgeons at KUMC; none performed more than $12 \%$ of the cases.

Conclusion: Number of harvested nodes is related to other prognostically significant parameters primarily related to tumor biology. The potential impact of surgeon's experience and the type of surgery performed needs further evaluation.
\end{abstract}

Keywords: Lymph node recovery, colectomy specimens, colorectal adenocarcinoma.

\section{INTRODUCTION}

Total number of lymph nodes (LNs) harvested in colectomy specimens for colorectal adenocarcinoma, serves an intricate role in determining adequacy of tumor resection and prognostication. Recent data suggest that a higher number of LNs evaluated in colectomy specimens is associated with better survival, regardless of the pathologic findings [1-3]. Multiple studies suggest that at least 12 harvested LNs in a colectomy specimen are required for accurate correlation with survival [4-7]. Unfortunately this criterion is only achieved in a minority of colon cancer operations $[8,9]$. While some investigators are advocating strict adherence of the surgeons to the fundamental principles of colon cancer surgeries, others are calling on the pathologists to be more aggressive in their search for those

*Address correspondence to this author at the Department of Pathology and Laboratory Medicine, University of Kansas Medical center, Kansas City, Kansas, 66160, USA; Tel: (913) 588-1185; Fax: (913) 588-8780;

E-mail: otawfik@kumc.edu
LNs. As a result of this debate, concerns have been raised about the adequacy of surgical resection and the thoroughness of the pathologic examination.

At present the American College of Surgeons, the American Society of Clinical Oncology and others are advocating the harvesting of at least 12 LNs in colectomy specimens for adequate assessment $[4,10]$. Unfortunately, the number of LNs harvested is not only being used as a benchmark for both surgeons and pathologists, but is also proposed to be used as a basis for payment strategies to surgeons and institutions by insurance companies. However, the reality is that the Commission on Cancer of the American College of Surgeons has not made any final recommendations as of yet. In addition, recent published studies contradict the prognostic value of LN adequacy and argue that any association is more complex and is influenced by a variety of confounding variables $[11,12]$.

The objective of this study is to evaluate the impact of several key confounding tumoral and non tumoral factors on harvesting $\geq 12$ LNs per colectomy specimen acquired from 
patients with colorectal adenocarcinoma from two institutions.

\section{MATERIALS AND METHODS}

Three hundred and six colon cancer colectomy specimens from 2 academic medical centers, including 177 from Kansas University Medical Center (KUMC) and 129 from The Kansas City Veterans Affairs Medical Center (VAMC), with surgery conducted from 2000 to 2007 are included in the study. Factors evaluated included tumor size, grade, stage, tumor location, number of positive LNs, number of harvested LNs, and length of colectomy segment removed. In addition, institutional site (KUMC or VAMC) and the surgeon of record were recorded. All clinical and histologic data were collected from surgical pathology records and recorded in a data base. Data were identified by date of surgery and by surgical pathology specimen number; but no other Protected Health Information (PHI) were collected. This is a retrospective study involving past pathology reports. Patient identification (except as noted above for specimen identification) was removed from all study material. No threat was posed to the patients' health, treatment or privacy. The studies were performed with the approval from the institutional review board at the University of Kansas Medical Center.

\section{Statistical Considerations}

Descriptive statistics were employed to characterize various clinical and pathological variables. We reported means, standard deviations, and $95 \%$ confidence intervals for parametric variables. Medians and interquartile ranges were used for data that are not normally distributed. Frequencies were reported for categorical variables. Comparisons of numerical values between groups (site, surgeon, etc.) were performed by t-test for normally distributed data or by Mann-Whitney test or Kruskal-Wallis test for non-parametric variables. Comparison between categorical variables was performed by Chi-square test. Multiple linear regressions were used to assess the relationship between number of positive LNs and each of the clinical and pathologic variables collected. Partial correlation coefficients were provided to describe the association of node positivity and each of the factors, while eliminating or controlling for the effect of the remaining variables. Pearson's correlation coefficient was used for normally distributed date; Spearman's correlation coefficient was used if the data were skewed.

\section{RESULTS}

The results of our study show several factors impacting the likelihood to harvest at least $12 \mathrm{LNs}$ per colectomy specimen. These factors have been divided into two categories: 1) tumor related factors and 2) procedural or nontumor related factors.

\section{Tumor Factors}

When cases were divided between those that did or did not achieve a yield of at least12 LNs, tumor size, grade and stage were of significant impact. In those specimens where $\geq 12$ LNs were identified, median tumor size was $4.5 \mathrm{~cm}$ in greatest dimension, compared to $3.2 \mathrm{~cm}$ for those specimens where less than 12 LNs were harvested ( $p$ value $<0.001$,
Mann-Whitney test, Fig. 1). This finding held true whether surgeries were performed at KUMC or at VAMC (data not shown). Table 1 shows that tumor grade influenced the adequacy of LN assessment. Similarly for specimens with tumors of higher stages (T3/T4) the yield of $\geq 12$ LNs per specimen was higher. There was a significant positive correlation between tumor grade and stage and yield of $\geq 12$ LNs per specimen $(\mathrm{p}$ value $=0.035$ and $\mathrm{p}$ value $<0.05$, respectively). A higher percentage of cases with $\geq 12$ harvested LNs were identified in poorly differentiated tumors as compared to moderately and well differentiated tumors (68\% vs $50 \%$ vs $37 \%$, respectively).

Table 1. Relationship Between Tumor Grade and Number of Resected Lymph Nodes in Colorectal Resection Specimen for Adenocarcinoma

\begin{tabular}{|c|c|c|c|}
\hline Tumor Grade* & $\begin{array}{c}\text { Less than } \\
12 \text { Nodes Resected }\end{array}$ & $\begin{array}{c}12 \text { or More } \\
\text { Nodes Resected }\end{array}$ & Total \\
\hline $\begin{array}{c}\text { Well } \\
\text { differentiated }\end{array}$ & $\begin{array}{c}12 \\
63 \%\end{array}$ & $\begin{array}{c}7 \\
37 \%\end{array}$ & 19 \\
\hline $\begin{array}{l}\text { Moderately } \\
\text { differentiated }\end{array}$ & $\begin{array}{l}121 \\
50 \%\end{array}$ & $\begin{array}{l}122 \\
50 \%\end{array}$ & 243 \\
\hline $\begin{array}{c}\text { Poorly } \\
\text { differentiated }\end{array}$ & $\begin{array}{c}14 \\
32 \%\end{array}$ & $\begin{array}{c}30 \\
68 \%\end{array}$ & 44 \\
\hline Total & $\begin{array}{r}147 \\
48 \%\end{array}$ & $\begin{array}{r}159 \\
52 \%\end{array}$ & 306 \\
\hline
\end{tabular}

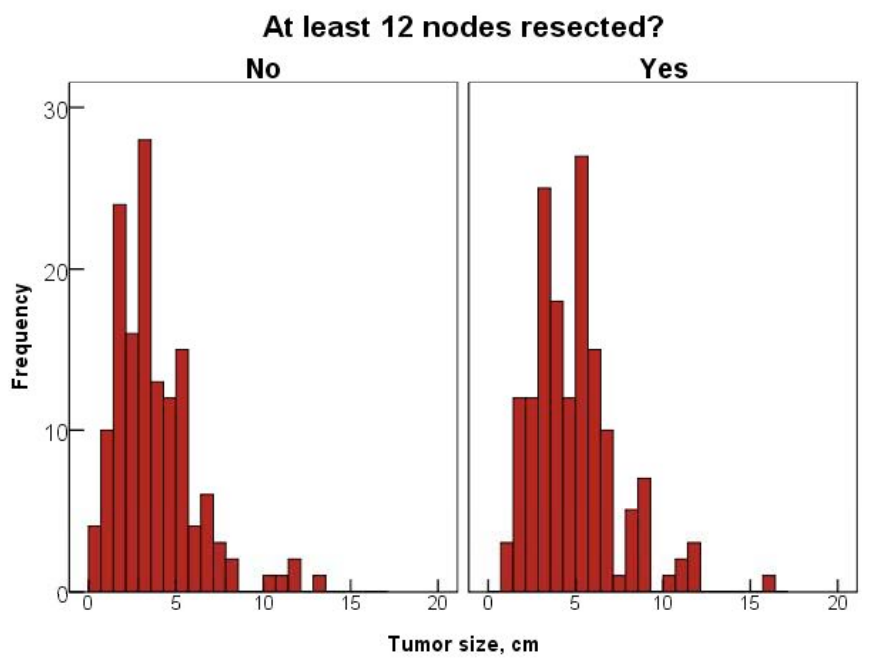

Fig. (1). The influence of tumor size on adequacy of nodal assessment in colorectal adenocarcinoma resection specimens. The likelihood of harvesting 12 or more nodes correlated with larger tumors.

The likelihood of harvesting $\geq 12 \mathrm{LNs}$ was also influenced by tumor location of resection $(\mathrm{p}<0.001$, KruskalWallis test). More LNs were harvested from the right colon (median=13 LNs), followed by descending (12 LNs), transverse and rectosigmoid (10 LNs, each). Tumor located within the right colon had the highest percentages of $12 \mathrm{LNs}$ or more $(66 \%)$. That was followed by descending colon tumor $(61 \%)$, then rectosigmoid tumors $(41 \%)$ and transverse colon tumors $(36 \%)$ (Table 2$)$. When we studied the relationship between tumor size and tumor location the 
right colon housed the largest tumors (median size $4.5 \mathrm{~cm}$ ), followed by descending colon $(4.0 \mathrm{~cm})$ and rectosigmoid and transverse colon tumors $(3.5 \mathrm{~cm}$, each) (Fig. 2).

Table 2. Relationship Between Tumor Location and Number of Resected Lymph Nodes in Colorectal Resection Specimen for Adenocarcinoma

\begin{tabular}{|c|c|c|c|}
\hline $\begin{array}{l}\text { Location of } \\
\text { Resection* }\end{array}$ & $\begin{array}{l}\text { Less than } \\
\text { 12Nodes Resected }\end{array}$ & $\begin{array}{l}12 \text { or More } \\
\text { Nodes Resected }\end{array}$ & Total \\
\hline $\begin{array}{c}\text { Cecum/ } \\
\text { Ascending Colon }\end{array}$ & $\begin{array}{c}39 \\
34 \%\end{array}$ & $\begin{array}{c}75 \\
66 \%\end{array}$ & 114 \\
\hline $\begin{array}{l}\text { Transverse } \\
\text { Colon }\end{array}$ & $\begin{array}{c}16 \\
64 \%\end{array}$ & $\begin{array}{c}9 \\
36 \%\end{array}$ & 25 \\
\hline $\begin{array}{l}\text { Descending } \\
\quad \text { Colon }\end{array}$ & $\begin{array}{c}12 \\
39 \%\end{array}$ & $\begin{array}{c}19 \\
61 \%\end{array}$ & 31 \\
\hline $\begin{array}{c}\text { Sigmoid } \\
\text { Colon Rectum }\end{array}$ & $\begin{array}{c}80 \\
59 \%\end{array}$ & $\begin{array}{c}56 \\
41 \%\end{array}$ & 136 \\
\hline Total & $\begin{array}{l}147 \\
48 \%\end{array}$ & $\begin{array}{r}159 \\
52 \%\end{array}$ & 306 \\
\hline
\end{tabular}

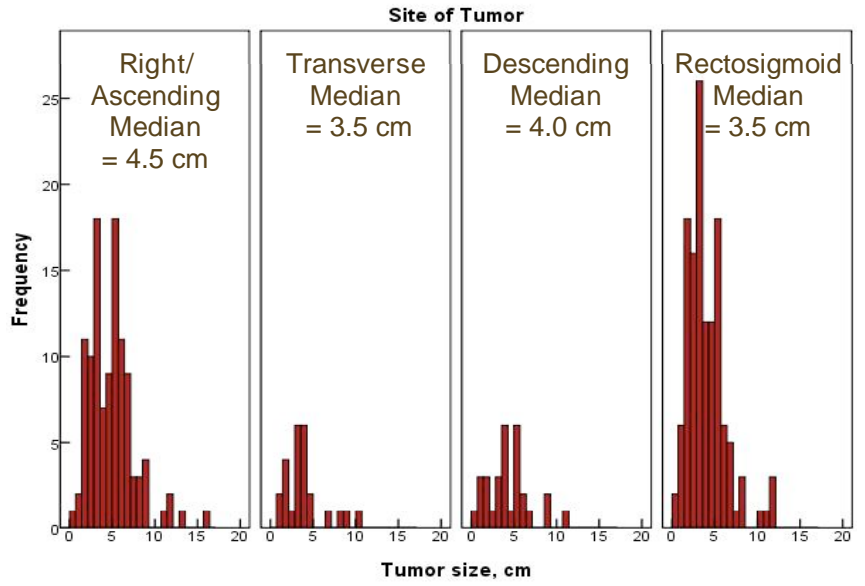

Fig. (2). Their isa relationship between tumor size and location for colorectal adenocarcinoma in colectomy specimens. Significantly larger tumors were located in the right colon $(\mathrm{p}=0.021$ KruskalWallis Test).

Although the number of positive nodes and whether there was nodal involvement correlated with tumor grade ( $\mathrm{p}<0.001$, Kruskal-Wallis test; $\mathrm{p}=0.004$, Chi-square test), there was no statistically significant correlation of whether or not at least 12 LNs were harvested with number of positive nodes, evidence of nodal involvement, tumor site or linear length of specimen. Table $\mathbf{3}$ demonstrates the lack of relationship between at least 12 LNs harvested and the ability to detect nodal involvement.

\section{Procedural and Non Tumor Related Factors}

There was no impact of institutional site on the relationship between our ability to harvest 12 or more LNs and tumor location. The highest percentages of cases with $12 \mathrm{LNs}$ or more continued to be from right colon tumors, with the same sequence at both institutions. However there was a significant difference between the 2 institutions as far as the number of nodes collected. Surgeries performed at the VAMC were more likely to yield $12 \mathrm{LNs}$ or more /specimens (Table 4, p < 0.001 ). Institutional differences were not related to tumor location, as there was no significant difference between tumors resected from the different sites per institutions (Table 5).

Table 3. No Relationship Between 12 or More Harvested Lymph Nodes and Evidence of Nodal Metastasis in Colorectal Specimens for Adenocarcinoma

\begin{tabular}{|c|c|c|c|}
\hline $\begin{array}{c}\text { Evidence of } \\
\text { Nodal } \\
\text { Involvement* }\end{array}$ & $\begin{array}{c}\text { Less than } \\
\text { 12 Nodes } \\
\text { Resected }\end{array}$ & $\begin{array}{c}\text { 12 or More } \\
\text { Nodes } \\
\text { Resected }\end{array}$ & Total \\
\hline \hline No & 93 & 94 & 187 \\
\hline Yes & $50 \%$ & $50 \%$ & 119 \\
\hline Total & 54 & 65 & $55 \%$ \\
\hline $\mathrm{p}=0.27$ Fishers Exact Test. & $\mathbf{1 4 7}$ & $\mathbf{1 5 9}$ & $\mathbf{3 0 6}$ \\
\hline
\end{tabular}

Table 4. Influence of Institutional Site on Whether 12 or More Lymph Nodes Are Harvested in Colectomy Specimen for Colorectal Adenocarcinoma

\begin{tabular}{|c|c|c|c|}
\hline $\begin{array}{c}\text { Institutional Site } \\
\text { of Surgery }\end{array}$ & $\begin{array}{c}\text { Less than } \\
\text { 12 Nodes Resected }\end{array}$ & $\begin{array}{c}\text { 12 or More } \\
\text { Nodes Resected }\end{array}$ & Total \\
\hline \hline KUMC & 101 & 76 & 177 \\
\hline VAMC & $57 \%$ & $43 \%$ & 129 \\
\hline Total & $36 \%$ & $64 \%$ & \\
\hline * $p<0.001$ Chi-Square Test. & $\mathbf{1 4 7}$ & $\mathbf{1 5 9 *}$ & $\mathbf{3 0 6}$ \\
\hline
\end{tabular}

Table 5. Relationship Between Tumor Location and Institutional Site on Whether 12 or More Lymph Nodes Are Harvested in Colectomy Specimen for Colorectal Adenocarcinoma

\begin{tabular}{|c|c|c|c|}
\hline Location of Resection* & KUMC & VAMC & Total \\
\hline \hline \multirow{2}{*}{ Cecum/Ascending Colon } & 71 & 43 & $\mathbf{1 1 4}$ \\
& $40 \%$ & $33 \%$ & $\mathbf{3 7 \%}$ \\
\hline \multirow{2}{*}{ Transverse Colon } & 17 & 8 & $\mathbf{2 5}$ \\
& $10 \%$ & $6 \%$ & $\mathbf{8 \%}$ \\
\hline \multirow{2}{*}{ Descending Colon } & 14 & 17 & $\mathbf{3 1}$ \\
& $8 \%$ & $13 \%$ & $\mathbf{1 0 \%}$ \\
\hline \multirow{2}{*}{ Sigmoid Colon Rectum } & 75 & 61 & $\mathbf{1 3 6}$ \\
& $42 \%$ & $47 \%$ & $\mathbf{4 4 \%}$ \\
\hline Total & $\mathbf{1 4 7}$ & $\mathbf{1 2 9}$ & $\mathbf{3 0 6}$ \\
\hline p $=0.22$ Ch-Square Test. & & &
\end{tabular}

We attempted to investigate factors impacting institutional difference on why more cases at the VAMC yielded 12 or more LNs as compared to KUMC, despite having the same individuals (pathology residents) grossly evaluating specimens at both institutions. We correlated surgeons experience in performing colectomies for tumor resections. Our results show that surgeons that had performed 10 or more colectomy 
procedures were more likely to have obtained specimens with at least 12 LNs (Table 6). It was noted, that 2 of 10 surgeons at the VAMC performed $76 \%$ of surgeons. In contrast, there were 21 surgeons at KUMC; none performed more than $12 \%$ of the cases.

Table 6. Influence of Number of Surgical Procedures Performed by Surgeons Annually on whether 12 or More Lymph Nodes are Harvested in Colectomy Specimen for Colorectal Adenocarcinoma

\begin{tabular}{|c|c|c|c|}
\hline $\begin{array}{l}\text { Number of } \\
\text { Cases* }\end{array}$ & $\begin{array}{c}\text { Less than } \\
12 \text { Nodes Resected }\end{array}$ & $\begin{array}{c}12 \text { or More } \\
\text { Nodes Resected }\end{array}$ & Total \\
\hline$<10$ & $\begin{array}{c}39 \\
63 \%\end{array}$ & $\begin{array}{c}23 \\
37 \%\end{array}$ & 62 \\
\hline$\geq 10$ & $\begin{array}{l}108 \\
44 \%\end{array}$ & $\begin{array}{l}136 \\
56 \%\end{array}$ & 244 \\
\hline Total & $\begin{array}{r}147 \\
48 \%\end{array}$ & $\begin{array}{l}159 \% \\
52 \%\end{array}$ & 306 \\
\hline
\end{tabular}

Another factor that seemed to influence adequacy of $\mathrm{LN}$ assessment is the length of the resected segment of colon. While resected specimens $22 \mathrm{~cm}$ or longer yielded a slightly higher number of LNs (median of 12) than did segments less than $22 \mathrm{~cm}$ (median of 11), this was only marginally statistically significant $(\mathrm{p}=0.032$, Mann-Whitney test $)$. However, for the more critical question of whether at least 12 LNs were harvested, there was no statistically significant difference based on segment length (adequacy of $55 \% \mathrm{vs}$ $48 \%, \mathrm{p}=0.25$, Chi-square test).

Finally, there was evidence that surgery date had an impact on number of harvested LNs. The likelihood of harvesting 12 nodes or more/specimen was significantly higher in surgeries performed in 2005 or later as compared to those performed prior to 2005 (Fig. 3). Again this observation was consistently noted in both institutions.

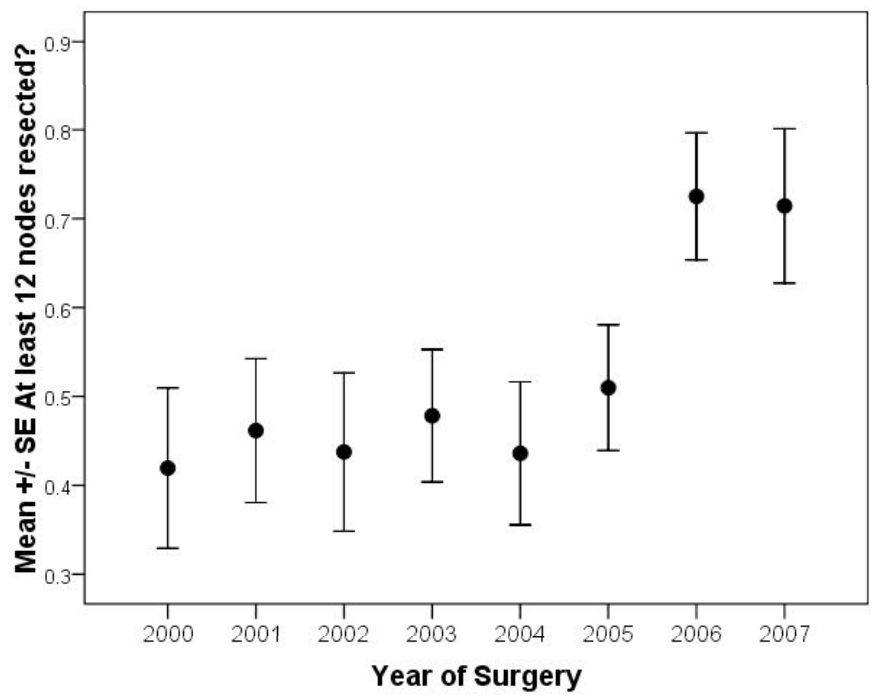

Fig. (3). A graph that shows the influence of surgery date on the number of harvested nodes in colectomy specimen for colorectal adenocarcinoma. Surgeries performed after 2005 were more likely to include 12 or more nodes per specimen $(\mathrm{p}=0.002$ Chi-Square
Test), an observation that consistently noted in both institutions $($ KUMC $\mathrm{p}=0.015$, VAMC $\mathrm{p}=0.036)$.

\section{DISCUSSION}

The results of our study suggest that the number of harvested LNs is not a straight forward process, but is related to several prognostically significant tumoral and non-tumoral parameters. The likelihood of harvesting 12 or more LNs is correlated with larger, higher grade and higher stage tumors. When tumor location is taken into account, more LNs were recovered form the right colon, followed by the descending, transverse, and lastly the rectosigmoid regions. Larger tumors were identified in the right colon and decreased in size in respect to the tumor location. It is yet to be determined if this effect is due to correlation or causation. These findings were consistent between institutions, even though the yield of at least 12 LNs differed between the two institutions.

Although the finding of node positivity correlated with tumor grade and stage, there was no significant correlation with whether 12 or more LNs were harvested with respect to tumor size, site or linear length of specimen. Our results are in total agreement with similar recent studies suggesting that tumor location, tumor grade [13], stage [14-16] and size is significantly impacting the number of identifiable LNs [17]. Shen et al. have recently reported that number of harvested LNs is most significantly associated with tumor location (right sided $v s$ left sided cancer), patient age and length of resected specimen [12].

It is interesting to note that since this benchmark has been utilized, the percentage of colectomy specimen that has yielded 12 or more LNs has increased over time. However, this number is still surprisingly low. In a recent study by Moug et al, inadequate LN retrieval, as defined by NCI, occurred in approximately $50 \%$ of the cases [18]. Similarly researchers using the National Cancer Data Base, have determined that only $17.5 \%$ of hospitals met or exceeded the benchmark rate of $75 \%$ compliance with the $12-\mathrm{LN}$ measure [8]. Fig. (3) shows that the likelihood of harvesting $12 \mathrm{LNs}$ or more per specimen improved with time, an observation that was consistently noted in both institutions. This was probably due to the increased diligence of pathologists and their supporting staff over time.

One of the strengths of our study is that the data are obtained from 2 different institutions (VAMC and KUMC) where the same group of individuals (pathology residents) performed gross evaluation of colectomy specimens at both institutions. This was unique in the study as it allowed us to evaluate other confounding factors in a more objective and direct way, excluding the potential impact of prosector's skills and techniques.

The potential relevance of other confounding factors such as host response, patient's age and the use of various techniques to facilitate identification of nodes was also reported by others with mixed results.

Non-tumor factors that appear to have an impact on number of nodes harvested are surgery date, institution site, surgeons' experience and/or technique as well as segmental resection length. Although it is interesting that those surgeons at the VAMC were more likely to have performed 
more than 10 surgeries over the 8 years evaluated, the potential impact of the surgeon's experience and the type of surgery performed need further evaluation. This was the most compelling factor when comparing the VAMC to KUMC. Several studies have suggested the potential impact of surgeons training and surgical techniques on lymph node harvesting [14, 15, 19-23]. It has been known that surgeons with more training and/or experience in colorectal procedures were more successful in obtaining adequate resections. Barbas el al, have recently shown that advanced fellowship training is associated with increasing number of lymph nodes analyzed [22]. If surgeons, pathologists and insurance companies wish to utilize the number of LNs harvested to determine adequacy of resection, these other variables must be factored into the equation.

Experience in adequately resected pericolonic mesenteric tissue and accompanying lymph nodes have been shown to be of prognostic significance [14, 15, 20-23]. Although we don't argue the numerous studies suggesting a better prognosis for patients in whom more nodes are examined, caution is advised when assessing the correlation between survival and number of LNs in colectomy specimens for colorectal cancer. Circumstances differ significantly for each patient, as well as each cancer surgery. The number of LNs assessed depends on multiple factors including, the surgeon, the pathologist, and the particular anatomy of the patient, (e.g. correlating number of LNs with survival does not hold for rectal cancer or any other scenario in which preoperative radiation or chemotherapy may destroy the nodes [24]). In a recent study by Wong et al, the authors retrospectively reviewed the 1995-2005 national Surveillance, Epidemiology, and End Results (SEER)-Medicare database, representing one fourth of the United States, for colon cancer colectomy LN examination rates in comparison to 5-year survival. Their analysis showed that higher numbers of identifiable nodes didn't correlate with higher rates of nodepositive disease nor did it affect patient survival [25]. Similarly, Kim et al. have demonstrated that additional lymph node examination from mesenteric tissue surrounding colorectal cancer in resection specimens was of no added clinical or pathologic relevance [26].

In conclusion, our results that the harvesting of at least 12 LNs in colectomy specimens for colorectal cancer is complex and the impact of various tumoral and non tumoral confounding factors should be taken into consideration before generalizing its use in guiding treatment or reimbursement. Creating simple solutions for quality improvements, especially when not based on sound evidence, such as setting quality benchmarks for number of nodes evaluated, although attractive to policy makers and payers, could lead to failure in achieving the desired improvement in patient outcomes. In fact it could be very disruptive to efforts aiming at developing effective strategies to solve the underlying problems.

\section{CONFLICT OF INTEREST}

The authors confirm that this article content has no conflict of interest.

\section{ACKNOWLEDGEMENTS}

Declared none.

\section{REFERENCES}

[1] Le Voyer TE, Sigurdson ER, Hanlon AL, et al. Colon cancer survival is associated with increased number of lymph nodes analyzed: a secondary survey of intergroup trial INT-0089. J Clin Oncol 2003; 21: 2912-9.

[2] Johnson PM, Porter GA, Ricciardi R, Baxter NN. Increasing negative lymph node cound is independently associated with imporved long-term survival in stage IIIB and IIIC colon cancer. J Clin Oncol 2006; 24: 3570-5.

[3] Chang GJ, Rodriguez-Bigas MA, Skibber JM, Moyer VA. Lymph node evaluation and survival after curative resection of colon cancer: systematic review. J Natl Cancer Inst 2007; 99: 433-41.

[4] Nelson H, Petrelli N, Carlin A, et al. National Cancer Institute Expert Panel. Guidelines 2000 for colon and rectal cancer surgery. J Natl Cancer Inst 2001; 93: 583-96.

[5] Bilimoria KY, Palis B, Stewart AK, et al. Impact of tumor location on nodal evaluation for colon cancer. Dis Colon Rectum 2008; 51 154-61.

[6] National Quality Forum Endorses Consensus Standards for Diagnosis and Treatment of Breast and Colorectal Cancer. Available at: http//216.122.138.39/pdf/news/prbreast-colon03-12-0 7.pdf [Accessed: December 27, 2007].

[7] Jass JR, O'Brien MJ, Riddell RH, Snover DC. Association of Directors of Anatomic and Surgical Pathology. Recommendations for the reporting of surgically resected specimens of colorectal carcinoma. Hum Pathol 2007, 38: 537-45.

[8] Bilimoria KY, Bentrem DJ, Stewart AK, et al. Lymph node evaluation as a colon cancer quality measure: a national hospital report card. J Natl Cancer Inst 2008; 100: 1310-7.

[9] Pinkwish MD. Lymph node evaluation as a colon cancer quality measure. CA Cancer J Clin 2009; 59: 2-4.

[10] Cancer Programs Practice Profile Reports (CP3 R), version 2. Measure specifications, Commision on Cancer, 1st released Nov. 2008.

[11] Wright FC, Law CH, Last L, et al. Lymph node retrieval and assessment in stage II colorectal cancer: a population -based study. Ann Surg Oncol 2003; 10: 903-9.

[12] Shen SS, Haupt BX, Ro JY, et al. Number of lymph nodes examined and associated clinicopathologic factors in colorectal carcinoma. Arch Pathol Lab Med 2009; 133: 781-6.

[13] Sarli L, Bader G, Iusco D, et al. Number of lymph nodes examined and prognosis of TNM stage II colorectal cancer. Eur J Cancer 2005; 41: 272-9.

[14] Evans MD, Barton K, Rees A, et al. The impact of surgeon and pathologist on lymph node retrieval in colorectal cancer and its impact on survival for patients with Dukes' stage B disease. Colorectal Dis 2008; 10: 157-64.

[15] Jacomo AL, Martinez CAR, Serra MMP, et al. prognostic impact of the lymph node metastatic ration on 5-year survival pf patients with rectal cancer not submitted to preoperative chemoradiation. J Coloproctol 2011; 31: 311-24.

[16] Morikawa T, Tanaka N, Kuchiba A, et al. Predictors of lymph node count in colorectal cancer resections. Data from US nationwide prospective cohort studies. Arch Surg 2012: 147: 715-23.

[17] Hus CW, Lin CH, Wang JH, Wang HT, Ou WC, King TM. Factors that influence 12 or more harvested lymph nodes in early stage colorectal cancer. World J Surg 2009; 33: 222-9.

[18] Moug SJ, Salanha JD, McGregor JR, Balsitis M, Diament RH. Positive lymph node retrieval ratio optimises patient staging in colorectal cancer. Br J Cancer 2009; 100: 1530-3.

[19] Le Voyer TE, Sigurdson ER, Hanlon AL, et al. Colon cancer survival is associated with increasing number of lymph nodes analyzed: a secondary survey of intergroup trial INT-0089. J Clin Oncol 2003; 21: 2912-9.

[20] Morris EJ, Maughan NJ, Forman D, Quirke P. Identifying stage III colorectal cancer patients: the influence of the patient, surgeon, and pathologist. J Clin Oncol 2007; 25: 2573-9.

[21] Valsecchi ME, Leighton J Jr, Tester W. Modifiable factors that influence colon cancer lymph node sampling and examination. Clin Colorectal Cancer 2010; 9: 162-7.

[22] Barbas A, Turley R, Mantyh C, Migaly J. Advanced fellowship training is associated with improved retrieval in colon cancer resections. J Surg Res 2011; 170: e41-6.

[23] Chou JF, Row D, Gonen M, Liu YH, Schrag D, Weiser MR. Clinical and pathologic factors that predict lymph node yield from 
surgical specimens in colorectal cancer. A population based study. Cancer 201; 116: 2560-70.

[24] Wichmann MW, Müller C, Meyer G, et al. Effect of preoperative chemotherapy on lymph node retrieval after resection of rectal cancer. Arch Surg 2002; 137: 206-10.
[25] Wong SL, Ji H, Hollenbeck BK, Morris AM, Baser O, Birkmeyer JD. Hospital lymph node examination rates and survival after resection for colon cancer. JAMA 2007; 298: 2149-54.

[26] Kim YM, Suh JH, Cha HJ, et al. Additional lymph node examination from entire submission of residual mesenteric tissue in colorectal cancer specimens may not add clinical and pathologic relevance. Hum Pathol 2007; 38: 762-7.

(C) Schafer et al.; Licensee Bentham Open.

This is an open access article licensed under the terms of the Creative Commons Attribution Non-Commercial License (http://creativecommons.org/licenses/by$\mathrm{nc} / 3.0 /$ ) which permits unrestricted, non-commercial use, distribution and reproduction in any medium, provided the work is properly cited. 